\title{
OS MUROS FALAM: \\ a presença e a ausência da cultura escrita na cidade de Lages/SC
}

THE WALLS TALK: the presence and the absence of culture written in the city of Lages/SC

v. 7, n. 2 [11]

ago/dez (2015)

Artigo
Maria Teresa Santos Cunha

Universidade do Estado de Santa Catarina

e-mail: mariatsc@gmail.com

Tania Cordova

Universidade do Estado de Santa Catarina

e-mail: taniacordova@bol.com.br

\section{Resumo}

O objetivo deste trabalho é problematizar as escritas da cidade, em especial as escritas ordinárias, que utilizam o muro como suporte. A presença (ou a ausência) das escritas representadas nos grafites e nas pichações contribui para a construção de sentidos de uma identificação urbana que recria a história a partir da perspectiva da memória e da territorialidade. A problematização das escritas (ou a ausência), respaldada pela abordagem da História Cultural, presentes nos muros que compõem o cenário urbano da cidade de Lages, localizada no interior do Estado de Santa Catarina, permitiram perceber um cotidiano permeado por interfaces de práticas discursivas materializadas pelas linguagens (como ações e representações da sociedade) que produzem, reproduzem e transformam as relações de poder e de pertencimento.

\section{Palavras-chave}

Escritas da cidade, Identificação urbana, Cultura Escrita.

\begin{abstract}
The objective of this work is to problematize the written city, especially the common written, using the wall for support. The presence (or absence) of represented the written in graffiti and the graffiti contributes to the construction of meaning of an urban identification that recreates the story from the perspective of memory and territoriality. The questioning of the written (or absence), supported by the approach of Cultural History, present in the walls that make up the urban setting of the city of Lages, located inside the state of Santa Catarina, allowed realize a everyday permeate for interfaces of discursive practices materialized by languages (like actions and representations of society) that produce, reproduce and transform the relations of power and belonging.
\end{abstract}

\section{Keywords}

Written City, Urban identification, Written Culture. 
El muro materializa la liberdad de expresión y siempre es preferible una pared escrita a outra gris y silenciosa. (Castillo Gómez, 2013).

Nos espaços citadinos pulsam e vibram signos de todas as espécies. E é nessa efervescência de informações que os vestígios da vida na cidade podem ser percebidas por olhares mais atentos. Olhares que buscam romper com as análises unidimensionais sobre o espaço da cidade passando a compreendê-la em sua (multi)dimensionalidade. Segundo Lefebvre (1991), os espaços da cidade devem ser perspectivados a partir de três nuances: espaço vivido, o espaço percebido e o espaço imaginado.

O espaço vivido é o espaço das práticas materiais, das relações físicas e materiais em consonância com a produção e reprodução social, é o espaço do trabalho, das comunicações, do mercado, da aglomeração urbana, dos trajetos e práticas cotidianas. O espaço percebido é o espaço simbólico das representações e sistemas de compreensão das práticas materiais. É o processo de interpretação das práticas cotidianas, produzidas seja pelo senso comum, seja pelas diferentes ciências que têm como objeto essas práticas espaciais/materiais. E por fim, é também o espaço imaginado, ou seja, o espaço de representação, de projeção, de construção de símbolos, de planos, de (re)significações das práticas espaciais.

Lefebvre (1991) sinaliza ainda, que, ao estudar o espaço citadino é necessário concebê-lo como um campo diferencial, onde, através de uma análise horizontal e vertical, buscam-se os indicadores da coexistência de tempos e espaços sociais, a existência de temporalidades diferenciadas que marcam a produção urbana.

$\mathrm{Na}$ cidade, as categorias espaço-tempo alicerçam-se também no aglomerado urbano, a exemplo do conceito de poder disciplinar, em Foucault, ou de esfera pública, em Habermas, entendida como a antítese da corte, do poder monárquico e lugar de concentração das instituições.

Michel De Certeau (1994) define a cidade estabelecida pelo discurso urbanístico a partir da possibilidade de uma tríplice operação: 1. A produção de um espaço próprio; 2. 0 estabelecimento de um não-tempo ou de um sistema sincrônico, para substituir as resistências inapreensíveis e teimosas das tradições; e 3. A criação de um sujeito universal e anônimo que é a própria cidade. "A cidade, à maneira de um nome próprio, oferece assim, a capacidade de conceber e construir o espaço a partir de um número finito de propriedades estáveis, isoláveis e articuladas uma sobre a outra" (CERTEAU, 1994, p. 173).

$\mathrm{Na}$ perspectiva do conceito operatório proposto por Certeau, é "nesse lugar [cidade] organizado por operações especulativas e classificatórias, que se combinam gestão e eliminação" (1994, p. 174), ou seja, ao abordar a cidade, a investigação histórica deve considerar como objeto de análise as práticas singulares e plurais que o contexto urbano pode 
gerar ou suprimir, considerando que há um aparato ideológico que determinará o incluído ou o excluído dos meios, entremeios e margens que compõem a cidade e que sustentam os sentidos que nela coabitam, sendo que a natureza dessa relação coexiste com os modos como são significados os espaços urbanos comuns (ruas, praças, muros, entre outros).

O sujeito ao inserir-se neste espaço inconcluso e polifônico, inscreve-se no social e, ao agir, suas ações adquirem sentidos inerentes a um sistema de comportamento social, uma vez dirigida a objetivos específicos e refratada por meio do real da cidade e de suas memórias (IAPECHINO, 2013, p. 3).

Os sentidos da cidade se materializam na língua, nas imagens, nos sons, nos instantes, nos instantâneos, nos rastros, nas texturas, (...), nas cores, [nas escritas que nela se espalham]. Os sentidos da cidade se textualizam e seus efeitos se impregnam do cotidiano pensado e vivido (IAPECHINO, 2013, p. 3). Desta forma, as linguagens produzidas nos espaços urbanos, em suas distintas materialidades, possibilitam ao sujeito, diferentes ressignificações dada à relação que se estabelece entre ele e a cidade, numa dimensão discursiva, ou seja, "num espaço habitado de memória, de subjetividades, a história se formula em/por um sujeito urbano que, à medida que produz sentidos na cidade - textualizando sua relação com ela constrói sua identidade (IAPECHINO, 2013, p. 3).

A vila de Lages, fundada em 22 de novembro de 1766, localiza-se na região do planalto de Santa Catarina e foi planejada para ser, num primeiro momento, um local estratégico para servir como ponto de defesa do território português, frente à possível expansão do território espanhol. No entanto, diante do crescente mercado consumidor de gado de corte e de muares - espécie de mula utilizada como meio de transporte - na região Sudeste e Nordeste, a vila incorpora uma nova função que é a de servir como apoio a esse mercado uma vez que se localizava entre o Rio Grande do Sul - centro produtor - e São Paulo - centro de comercialização e consumo - (PEIXER, 2002).

Essa configuração permaneceu até meados da década de 40 do século $X X$, quando ocorreu o deslocamento da economia vinculada às atividades da pecuária extensiva para a economia fornecedora de bens e serviços ligada à indústria madeireira. Esse deslocamento econômico, conforme Peixer (2002) será responsável por um novo processo de constituição do espaço urbano em Lages. Surgia uma nova configuração que buscava sintonizar os desejos da urbe às proposições de modernização que vinham ocorrendo em outros centros urbanos do país.

A mesma autora afirma que foi somente nas décadas de 40 e 50 do século $X X$ que o "bater dos martelos, o vaivém dos pedreiros e dos carretões carregados de pedras" (PEIXER, 2002, p.51), possibilitaram a criação de novos espaços na urbe, espaços que começam a estruturar, a delinear a cidade para a qual o olhar recai, na contemporaneidade, na busca por vestígios, por marcas de escritas distribuídas, espalhadas pela cidade tendo como suportes os muros e as paredes que circunscrevem os espaços públicos e privados na região central da cidade. $O$ intento deste movimento é perceber a produção das escritas ordinárias, que utilizam 
o muro como suporte, como práticas sociais que contribuem para entender o deslocamento da atenção histórica dos grandes modelos para as práticas cotidianas, apropriadas e ressignificadas pelos sujeitos comuns.

O desenvolvimento da ação, de busca aos vestígios escritos nos muros, pressupõe duas vertentes apontadas por Certeau (2000), como histórica e etnológica. A vertente histórica busca organizar seus dados com relação às expressões conscientes e desenvolve-se na continuidade das marcas deixadas pelos processos escriturários onde se exprime o trabalho que constrói (faz) o tempo e que Ihe dá consciência através de um retorno de si mesma (Idem, p. 217). A etnológica, por sua vez, volta-se as condições inconscientes da vida social e utiliza-se da observação, percepção e descrição para conduzir a vertente histórica a uma narrativa problematizada.

De acordo com o dicionário etimológico, organizado por Cunha (2010), a palavra muro designa uma espécie de parede forte que circunda um recinto ou separa um lugar do outro. Retomar o significado de muro justifica-se pela alusão de que a prática do registro, da grafia neste tipo de suporte remonta à pré-história, período em que os hominídeos registravam nas paredes das cavernas questões referentes ao seu cotidiano, às suas formas de interpretar e se relacionar com o mundo. Em uma menção comparativa a essa necessidade de registro, Castillo Gómez (2013), sinaliza que a materialidade artificial da cidade contemporânea, com suas paredes e muros constituem para o homem de hoje, o mesmo que a pedra natural constituiu para o homem primitivo: um lugar para poder expressar-se.

A necessidade de sistematizar, registrar e disseminar, ao longo do tempo, produziu nas sociedades humanas o advento da escrita. No que tange o uso de paredes, como suporte de escrita, a sociedade egípcia na antiguidade, por exemplo, registrava fatos com hieróglifos (tipo de escrita na qual cada símbolo representa uma ideia) nas paredes dos templos, pirâmides, dentre outros espaços. Essa prática de registro egípcia remete, na contemporaneidade, a arte da grafitagem (graffiti/grafite). O termo grafite,

\footnotetext{
deriva do italiano graffiare, (...) [e] significa algo como riscar. Graffiti, palavra, entretanto banalizada, corresponde ao plural de grafito e designa uma 'marca ou inscrição feita num muro/parede'. Se podemos identificar vários espécimes de graffiti na rua, temos que reconhecer que apenas alguns podem ser identificados como expressões legítimas, de acordo com aquilo que, historicamente, se convencionou chamar graffiti, com base numa especificidade de linguagens, modos de produção e atmosfera cultural (CAMPOS, 2009,p. 148).
}

Segundo Djukich de Nery e Herrera (2008), no cenário mundial, o grafite começa a ganhar visibilidade com os movimentos juvenis e urbanos iniciados em maio de 1968, na França, e com a juventude rebelde norte-americana nos anos 70, onde essas juventudes começaram a construir movimentos de expressões visuais com conteúdos que buscavam romper com a norma estabelecida. Para estes movimentos, o muro foi o detentor da palavra que não circulava, que não era veiculada pelos meios de comunicação como a televisão ou o 
jornal, uma vez que estes meios encontravam-se distantes para estes movimentos (CASTILLO GÓMEZ, 2013).

No Brasil, o grafite só surge no final da década de 60 do século XX, como uma forma de protesto contra as ações da ditadura militar e, possivelmente, devem ter configurado uma função semelhante ao do movimento europeu e norte-americano, a de veicular um posicionamento, uma transgressão, uma reivindicação, entre outras. No Brasil, o ato de grafar os espaços citadinos apresenta-se sob duas características: a grafitagem e a pichação. Estas duas formas, apesar de utilizarem-se basicamente do mesmo tipo de suporte para a escrita (paredes e muros), diferenciam-se nas maneiras como são entendidas pela sociedade.

A pichação compreende um conjunto de escritas que não possui uma profundidade estética. É um tipo de escrita onde geralmente se escreve o nome do artista, uma frase de protesto, ou um símbolo com uma tipografia/tipologia própria, às vezes de difícil compreensão para quem não está inserido no grupo. A pichação, ainda, é na maioria das vezes registrada com apenas uma cor de tinta e localizada em locais de acesso mais limitado, e produzido de forma mais rápida. A pichação é vista, usualmente, como vandalismo, e é considerada crime e por conta disso tem sido combatida ${ }^{1}$.

Ao contrário da pichação, o grafite é caracterizado pela organização de registros mais elaborados, com mais cores e efeitos artísticos. A leitura de um grafite é complexa e por ter, na maioria das vezes, uma aparência mais agradável ao olhar, é socialmente aceito. É importante destacar que a diferença entre a pichação e o grafite é estética e não ideológica. No que diz respeito, a ideologia, os dois tipos de escrita em muros e paredes, têm o mesmo fundamento, que em resumo é passar, transmitir, produzir um sentido a partir de uma mensagem ao observador, ao transeunte. Nessa perspectiva, o grafite e a pichação configuram uma intencionalidade de escrita que é apropriada, ressignificada e posta a circular, uma vez que produzir este tipo de escrita está distante de ser apenas "chegar e pintar" um muro, uma parede, é uma mensagem transmitida, uma marca deixada no corpo da cidade. O que lemos na epiderme da cidade são manifestações desta identidade que usa os códigos de comunicação urbana para alcançar notoriedade (CAMPOS, 2009).

Ao esquadrinhar as ruas na região central da cidade de Lages em busca de vestígios de escritas em muros e paredes, depara-se com uma tímida produção caracterizada como pichação e com a ausência da grafitagem, com exceção da manifestação encontrada no centro da cidade (figura 1 ).

\footnotetext{
1 A lei que pune a pichação tem base na lei de crimes ambientais da Constituição Federal - Lei 9.605/1998, Art. 65. Pichar ou por outro meio conspurcar edificação ou monumento urbano: (Redação dada pela Lei no 12.408 , de 2011) tem pena de detenção, de 3 (três) meses a 1 (um) ano, e multa.§ 10 Se o ato for realizado em monumento ou coisa tombada em virtude do seu valor artístico, arqueológico ou histórico, a pena é de 6 (seis) meses a 1 (um) ano de detenção e multa.
} 


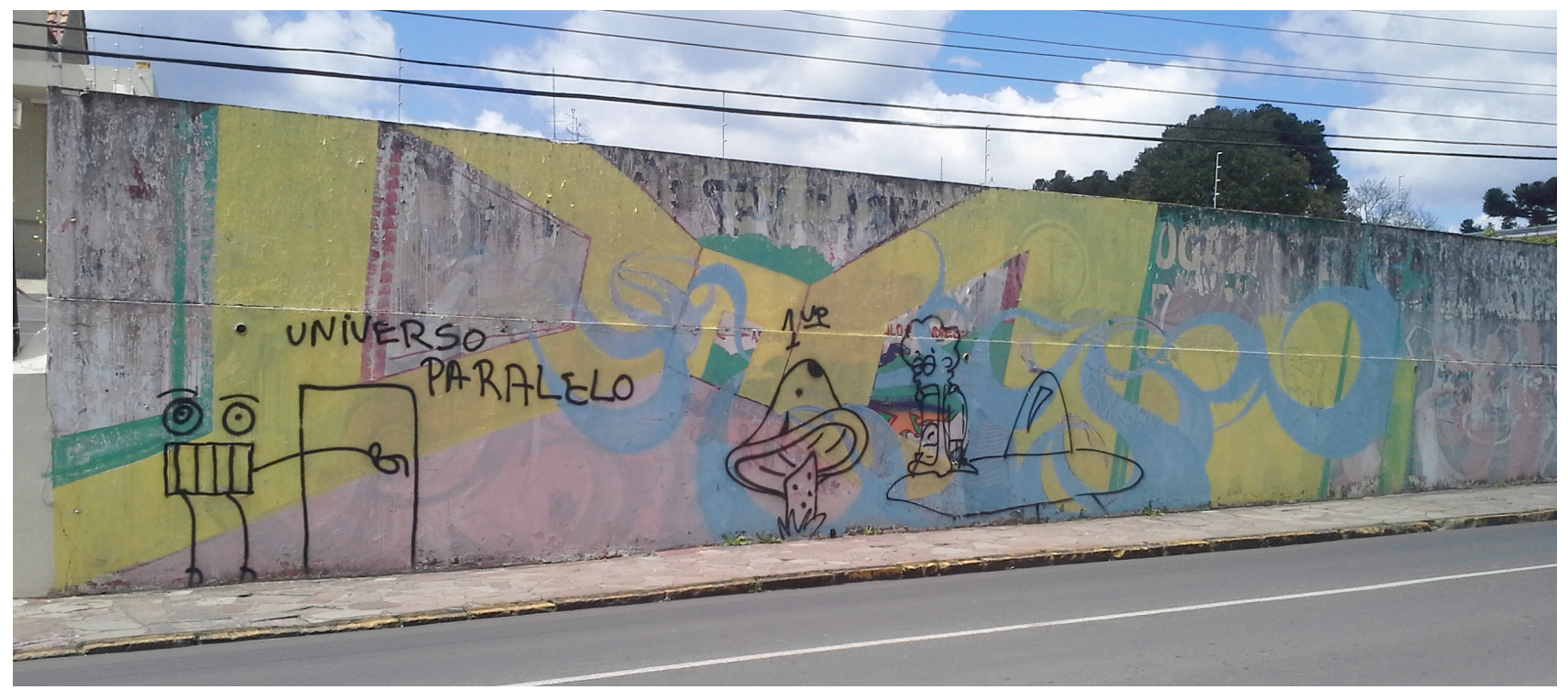

Figura 1 - Manifestação de Grafite (Rua Emiliano Ramos, Lages) - [Arquivo das autoras, março de 2015].

O que aproxima o registro neste muro com a grafitagem são as características como: traços geométricos, o uso de diferentes cores e a intenção de marcar uma ideia, uma representação. Ideia esta, inacabada, e ressignificada por outro autor, haja vista, as marcas e escritas que se sobrepõem à primeira intenção. Os desenhos em tinta preta e a escrita <universo paralelo>, possivelmente não faziam parte da proposta inicial. Os grafites, que nos grandes centros urbanos têm ganhado visibilidade, a exemplo da cidade de Florianópolis, capital do Estado de Santa Catarina, onde parte significativa de muros e paredes espalhados pela cidade vem sendo coberta por grafites e pichações, na cidade de Lages é ausente.

As manifestações de escritas enquadradas como pichações, são mais comuns, porém não numerosas, nas ruas do centro da cidade. Para este trabalho, foram selecionadas quatro representações, onde duas destas apresentam uma organização de escrita, com uma mensagem proposta e as demais com representações que caracterizam outro tipo de código.

$\mathrm{Na}$ primeira imagem (figura 2), o autor expressa, a partir do registro no muro, a intensidade de seus sentimentos fazendo com que o sujeito-objeto de seu amor seja reconhecido, seja visível às pessoas que circulam naquele espaço. Importante destacar que o lugar onde se localiza essa escrita é um espaço público (Biblioteca Pública), o que caracteriza um local frequentado por diferentes públicos, grupos que se apropriam de formas diferenciadas da mensagem transmitida, marcada na parede. Uma das intenções do grafite ou da pichação é também constituírem-se em um código passível de ser decifrado pelos pares, pelos sujeitos que estão inseridos em determinado grupo, ou que compreendam a intenção do que lhe é transmitido. 


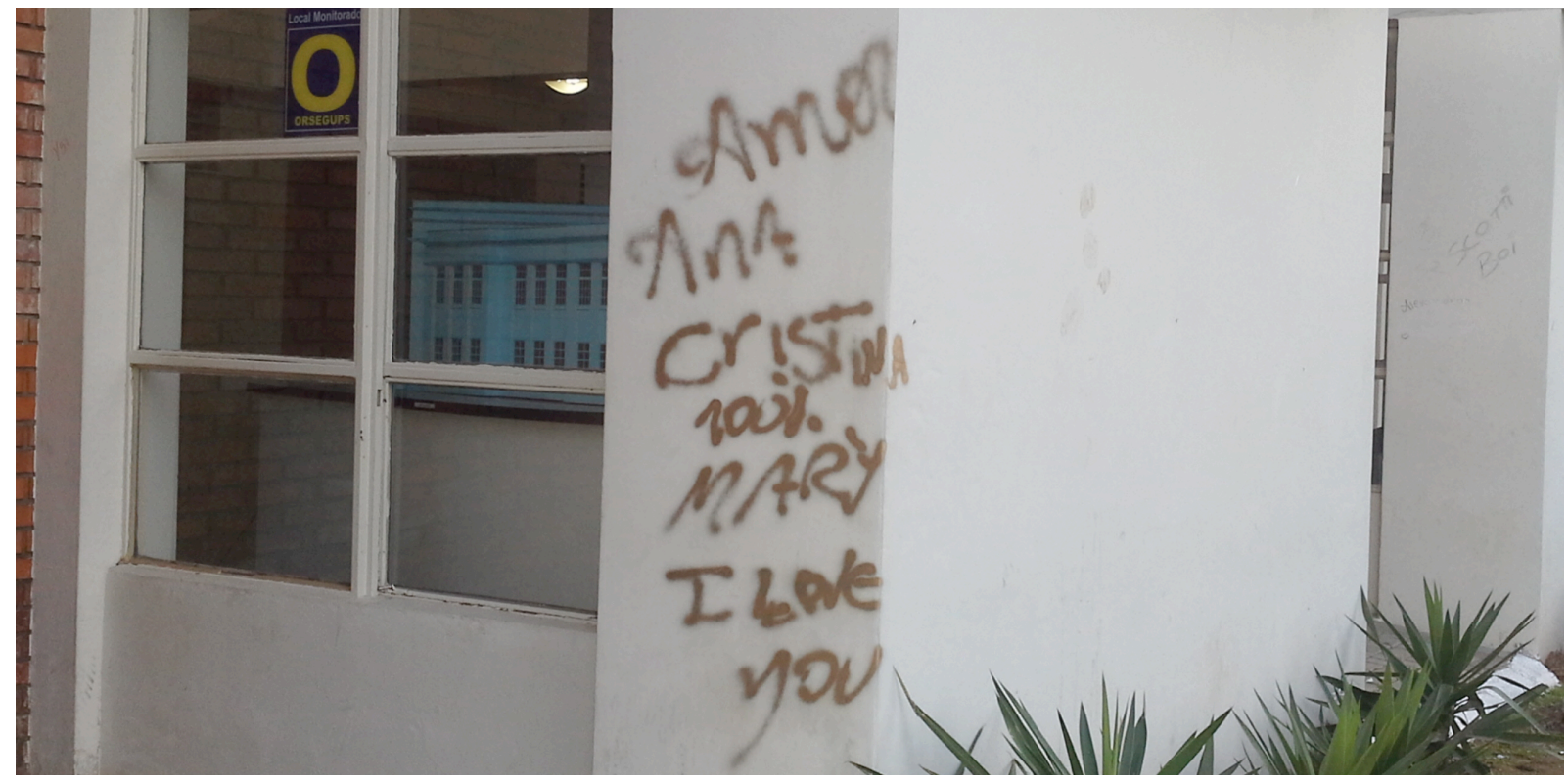

Figura 2 - Escrita romântica localizada no Parque Jonas Ramos - Tanque [Arquivo das autoras, março de 2015].

Na segunda representação (figura 3), a intenção da escrita é ideológica, caracterizada por uma marca de gênero, de caráter revelador de um discurso que percebe o feminismo como um movimento radical. A marca nesta manifestação pode dar pistas sobre a identidade do autor, uma vez que revela sua vinculação, seu posicionamento ideológico. No entanto, o corte representado pelo risco sobre a expressão < ideia radical > denota um arrependimento sobre o posicionamento, ou pode demonstrar uma tentativa de amenizar a posição expressada.

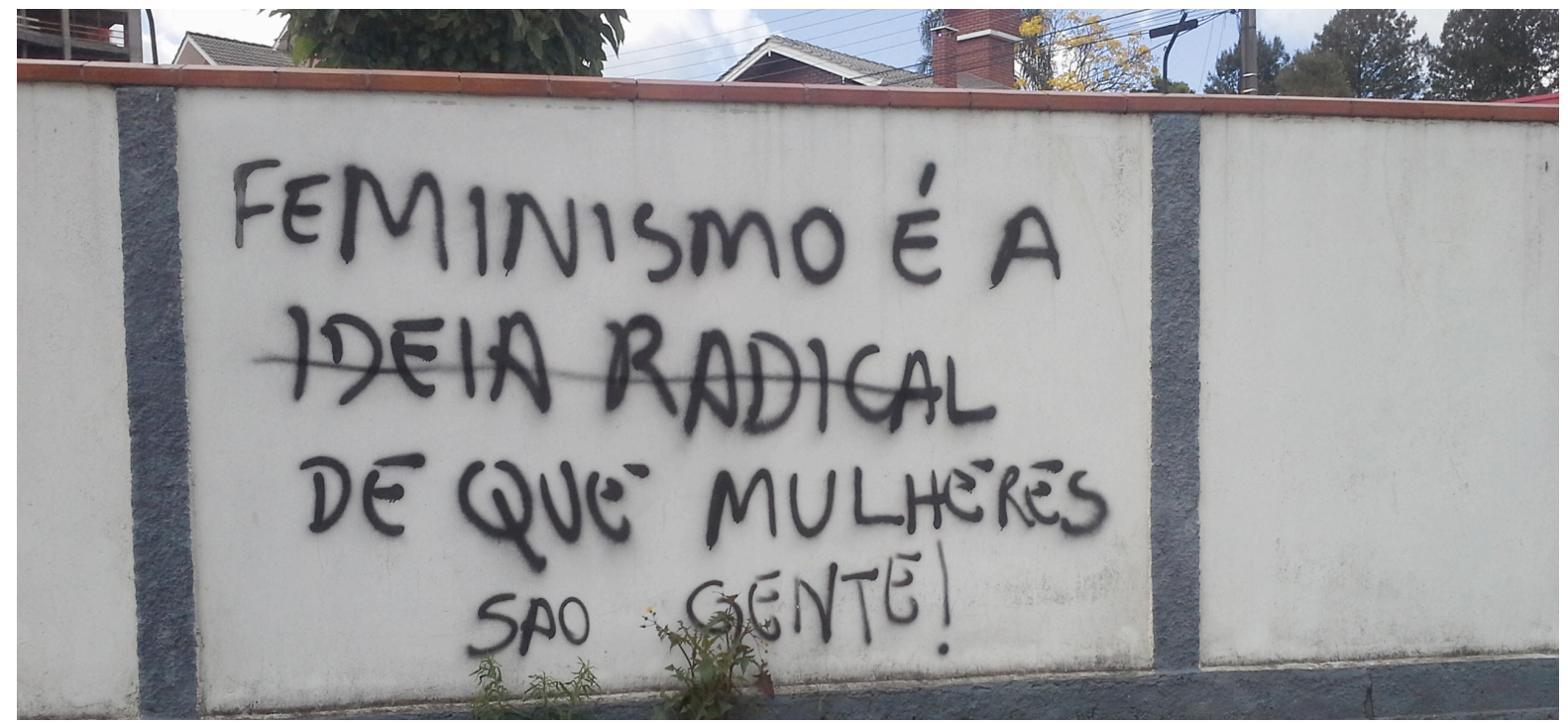

Figura 3 - Escrita ideológica, localizada na rua Dr. Walmor Ribeiro. [Arquivo das autoras, março de 2015]. 
Por fim, o lugar físico ocupado, por esta escrita no cenário urbano ${ }^{2}$ representa a ousadia do autor em desafiar, em agredir o sistema utilizando o muro para expressar seu posicionamento frente ao movimento feminista.

As outras duas pichações não contemplam uma sistematização escrita, ou algo que denote, num primeiro momento, uma intenção de mensagem ou um posicionamento frente a uma dada situação. As representações encontradas (figuras 4 e 5 ) são formadas por símbolos e desenhos. Djukich de Nery e Herrera (2008) sinalizam que este estilo de escrita foi difundido na América do Norte na década de 70 e igualavam-se aos 'tags' - letras do alfabeto, usualmente deformadas - e desenhos sem elementos verbais.

A ausência de elementos verbais não denota a não intenção de transmissão de uma mensagem ou de uma intencionalidade de escrita. Possivelmente, essas formas de expressão sejam indecifráveis para a larga maioria que desconhece as convenções pictóricas, técnicas que as constituem. No entanto, as mesmas assumem-se enquanto um veículo comunicador para um dado grupo que reconhece na grafia do muro, um elemento de pertença, de vínculo, de organização social.

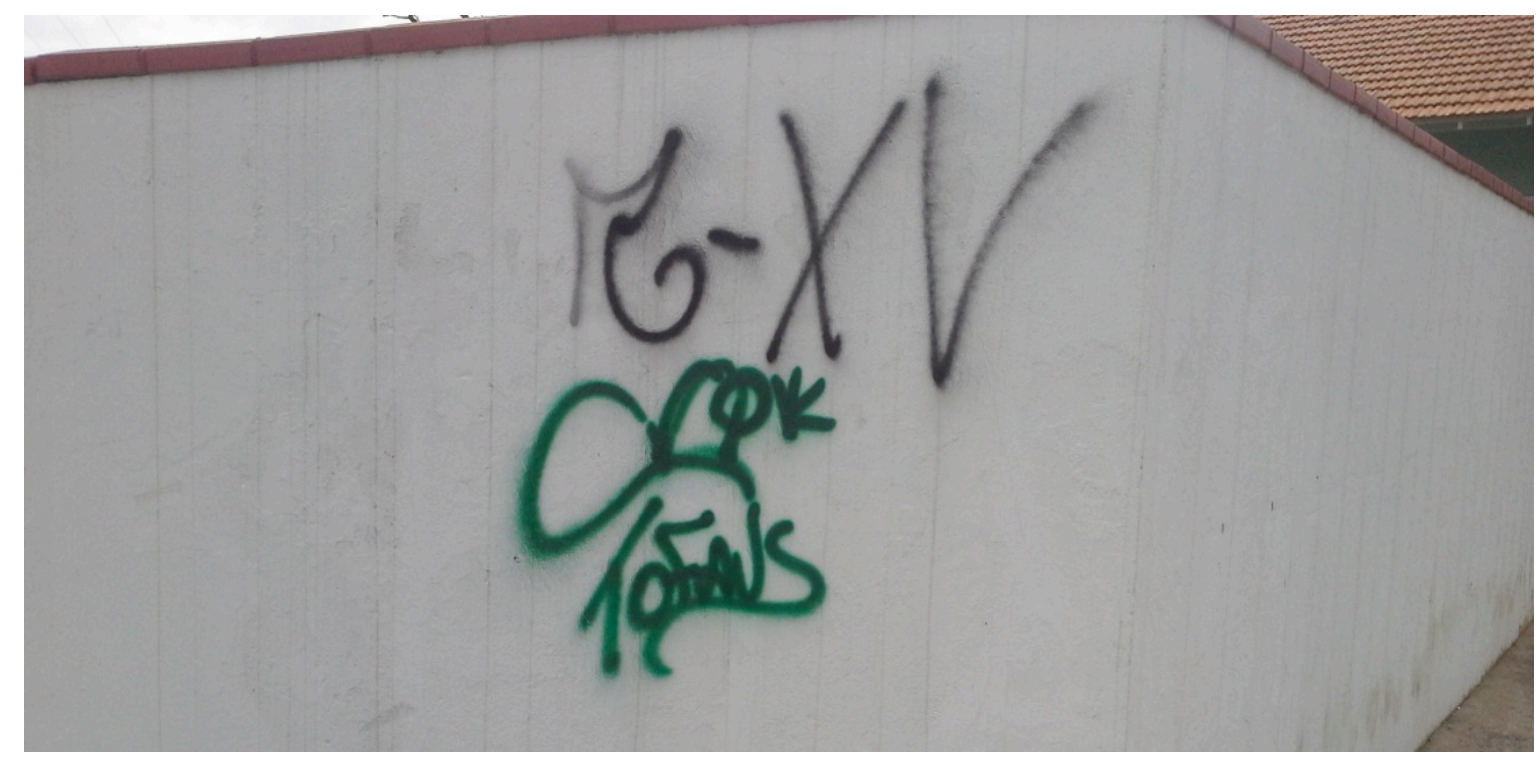

Figura 4 - Escrita em código, localizada na rua Dr. Walmor Ribeiro. [Arquivo das autoras, março de 2015].

\footnotetext{
${ }^{2}$ Este exemplo de pichação está localizado à Rua Doutor Walmor Ribeiro, local de intensa circulação de pessoas. Esta rua constitui-se em um dos principais acessos ao Estádio Municipal e ainda como meio de ligação entre bairros.
}

(c) Urbana: Rev. Eletrônica Cent. Interdiscip. Estud. Cid.

Campinas (SP)

v.7, n.2 [11]

p.120-131

ISSN 1982-0569 


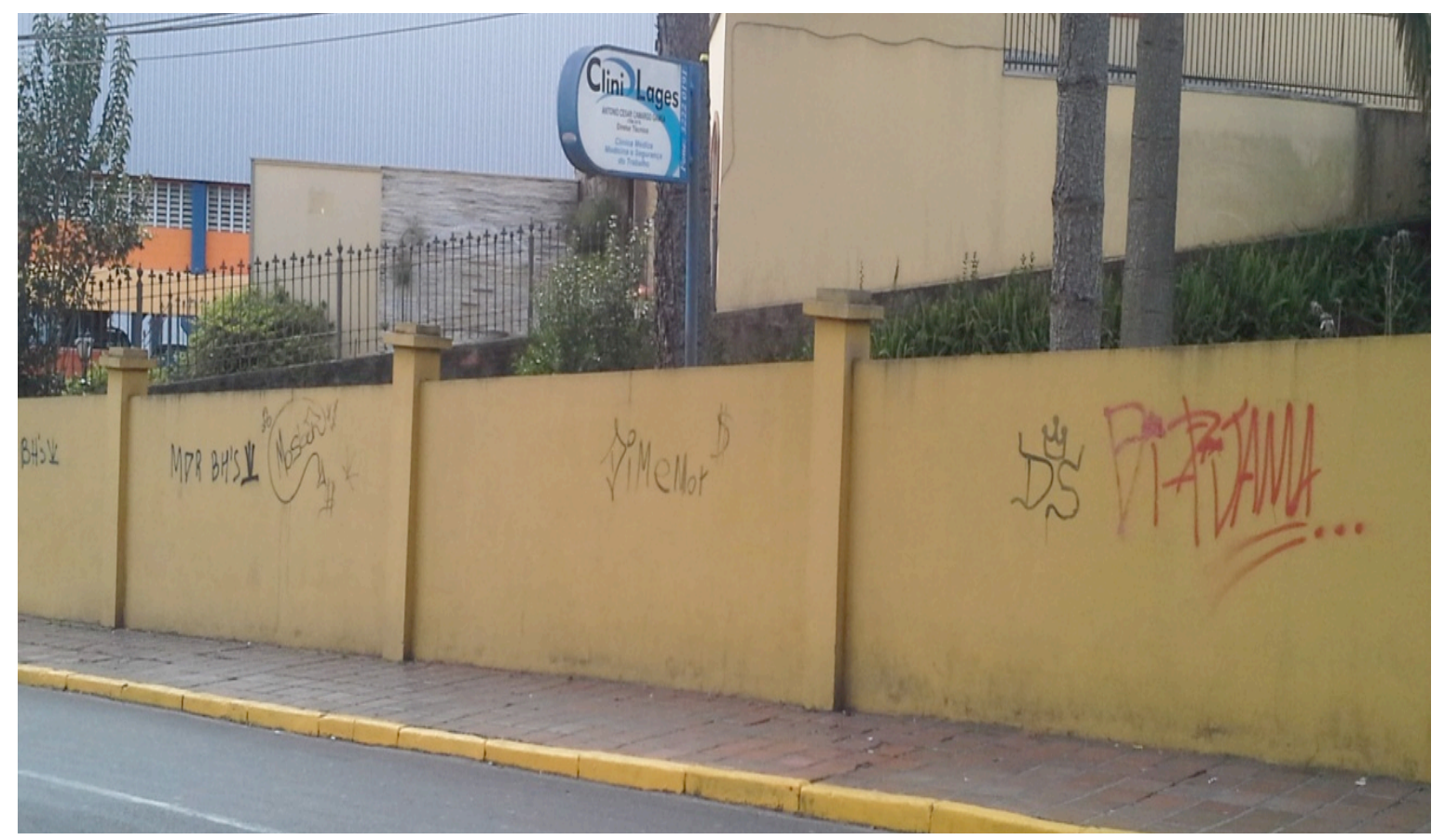

Figura 5 - Escrita em código, localizada no Parque Jonas Ramos - Tanque. [Arquivo das autoras, março de 2015].

Distantes de propiciarem uma interpretação sistemática, elaborada da mensagem que transmitem as representações, encontradas na região central da cidade de Lages, incorrem em problematizar, também, a intenção da grafia, de registro nos muros a partir do prazer em transgredir a norma social que proíbe escrever em locais públicos. Ao analisar o grafado é possível perceber que não há uma motivação de cunho ideológico, político, social, cultural. Mas, uma intenção em registrar uma marca, uma identificação, seja individual ou de reconhecimento de um grupo.

Em "As palavras e as coisas", Michel Foucault (2002), sinaliza que a cultura e os povos podem ser conhecidos e definidos de acordo com a sua linguagem. Assim, se o grafite e a pichação, como elementos constitutivos da linguagem permitem conhecer, problematizar aspectos da organização, da vida de uma determinada sociedade uma vez que permeiam o universo cotidiano onde o sujeito-autor das escritas põe em práticas linguagens que produzem, reproduzem e transformam os espaços em que se inserem, a ausência destas escritas no espaço citadino, também pode evidenciar a construção cultural desta sociedade.

Ao esquadrinhar os espaços citadinos, se observa, se comparado com outros centros urbanos, como a capital do estado - Florianópolis, por exemplo, a ausência de manifestações escritas. Observam-se espalhados pela cidade significativas extensões de muros e paredes em branco (figuras 6 e 7). Sobre os muros em branco Castillo Gómez (2013), sinaliza que estes, ao longo da história, sempre têm despertado a necessidade de expressão e a vontade de comunicação do ser humano. 


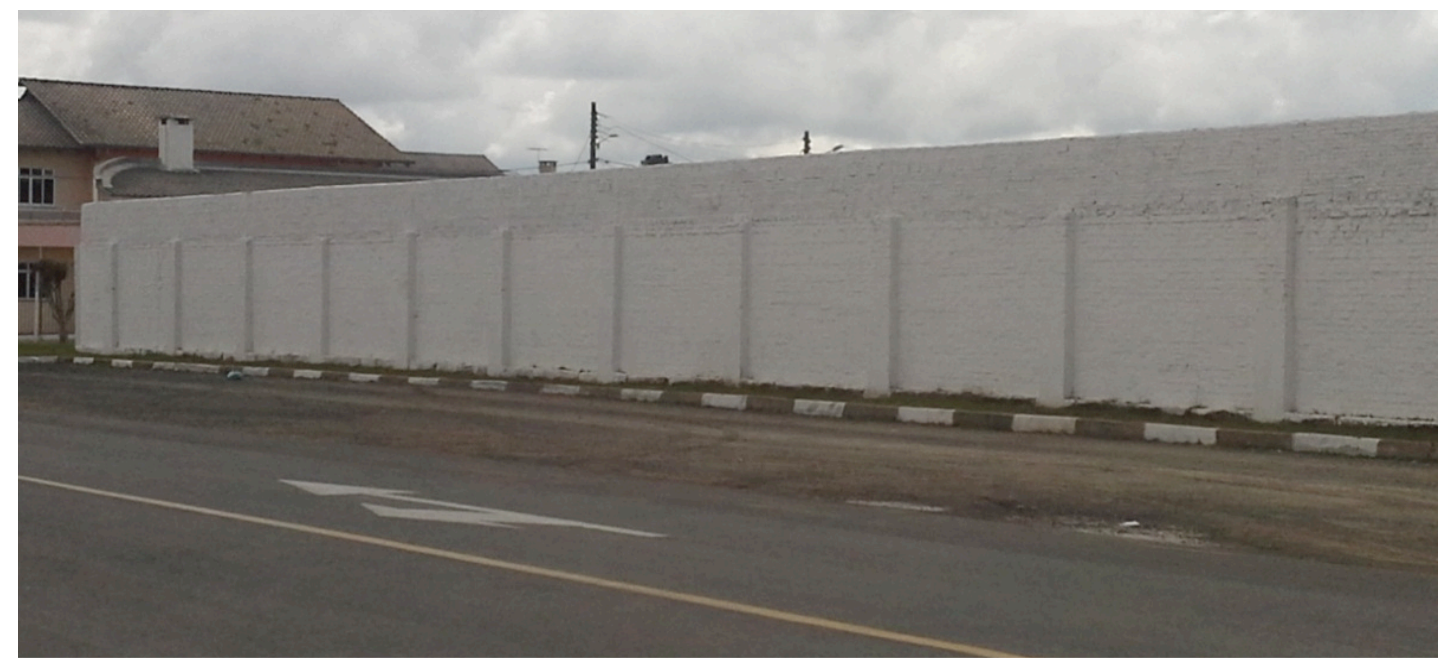

Figura 6 - Muro em branco, localizado nos fundos do Estádio Municipal. [Arquivo das autoras, março de 2015].

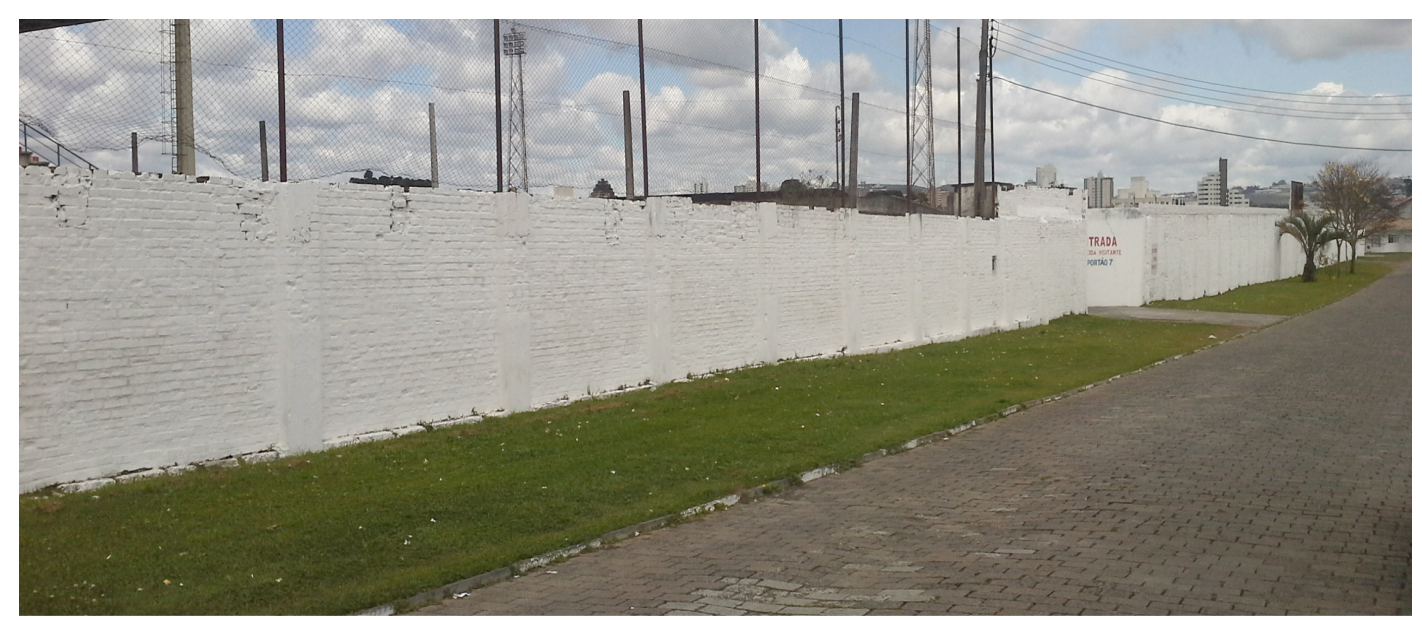

Figura 7 - Muro em branco, localizado no Estádio Municipal. [Arquivo das autoras, março de 2015].

A ausência de escrita (grafites e pichações), na cidade de Lages, localizada no interior do estado catarinense pode significar o oposto da proposição de Castillo Gómez (2013), isto é, a ausência deste tipo de escrita pode ser compreendida pela via do não interesse da população em registrar, em utilizar o muro, a parede como meio veiculador de suas reivindicações, de suas manifestações nas diferentes dimensões da vida social, política, cultural, econômica.

Um exemplo pode ser, hipoteticamente, construído a partir dos muros que circundam uma das maiores escolas públicas da cidade - Escola de Educação Básica Vidal Ramos Júnior. Em um momento de visíveis problemáticas no contexto educativo, haja vista os movimentos 
pela educação em circulação no Estado - Todos pela Educação; Movimento da Indústria pela educação, entre outros. O silêncio presente no muro pode denotar a alienação às causas educativas, um distanciamento aos problemas que perpassam a educação, enfim a ausência da escrita no muro, neste espaço, pode possibilitar a investigação a partir de diferentes enquadramentos.

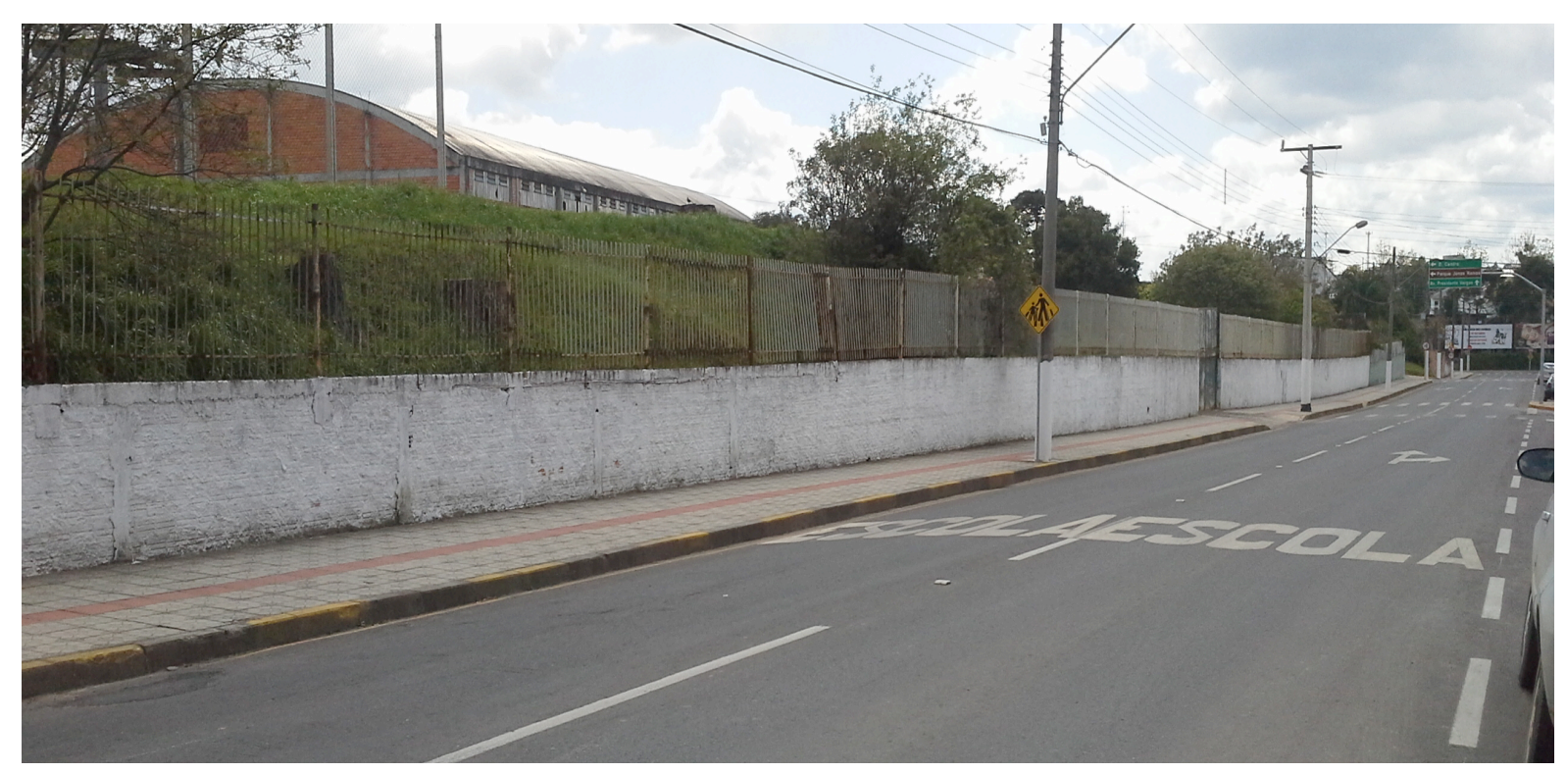

Figura 8 - Muro em branco, localizado nos fundos da E.E.B. Vidal Ramos Júnior. [Arquivo das autoras, março de 2015].

A ausência do escrito também pode ser dimensionada, problematizada a partir da construção histórica da cidade, onde a tensão, o conflito, as práticas reivindicatórias estiveram (estão) distantes da realidade vivida pelos sujeitos, realidade esta, onde os sujeitos não se apropriam e não ressignificam o espaço da cidade como espaço possível ao abrigo de formas discursivas dissonoras, que denunciam o imbricar entre sistema e mundo vivido.

O grafite e a pichação, como manifestações da linguagem humana são fenômenos essencialmente urbanos que abrem espaços para a comunicação, que nem sempre é vista e entendida como legal, dados os suportes, conteúdos, locais em que se inserem. No entanto, por trás destas diversas formas de escrita encontradas nos espaços em Lages: escrita romântica, posicionamento ideológico, códigos, escritas que marcam ou demarcam um dado espaço, encontram-se intenções de registrar na urbe uma dada mensagem, uma vez que se a cidade é o contexto onde relações e culturas particulares se desenvolvem, também é o território onde formas particulares de comunicar se desenham. O muro é, desde os tempos mais remotos, suporte privilegiado para a inscrição de símbolos, sendo apropriado por diferentes pessoas, grupos e instituições, com objetivos, funções e poderes distintos.

Se o muro é um lugar de visibilidade das práticas cotidianas e sociais, porque na cidade de Lages existem significativas extensões de muros sem escrita? Por que, nesta cidade, o uso do muro está distante de materializar-se como forma de liberdade de expressão? Por

(c) Urbana: Rev. Eletrônica Cent. Interdiscip. Estud. Cid. $\quad$ Campinas (SP) $\quad$ v.7, n.2 [11] $\quad$ p.120-131 ISSN 1982-0569 
que ainda, nos espaços citadinos são preferíveis muros em branco a um escrito? Fica assim, uma nova trajetória de exploração, um novo caminho para pesquisa histórica.

\section{REFERÊNCIAS}

CAMPOS, R. Entre as luzes e as sombras da cidade: visibilidade e invisibilidade no graffiti. Etnografica, vol. 13/1, maio de 2009, 145-170. Disponível em: http://www.scielo.oces.mctes.pt/pdf/etn/v13n1/v13n1a09. Acesso em: 02 mar. 2015.

CASTILLO GÓMEZ, A. Paredes sin palavras, pueblo callado. ¿Porque la Historía se representa em los muros?. Disponível em: http://dspace.uah.es/dspace/bitstream/handle/10017/6787/Paredes\%20Palabras.pdf?sequenc $\mathrm{e}=1$. Acesso em: 02 mar. 2015.

CERTEAU, M. de. A Invenção do Cotidiano: 1. Artes de fazer. Tradução de Ephraim Ferreira Alves, 9. Ed. Petrópolis, Rio de Janeiro: Vozes, 1994.

. A escrita da História. Tradução de Maria de Lourdes Menezes, 2.ed. Rio de Janeiro: Forense Universitária, 2000.

CUNHA, A. G. Dicionário etimológico da língua portuguesa. 4. Ed. revista pela nova ortografia. Rio de Janeiro: Lexikon, 2010.

DJUKICH de NERY, D.; HERRERA, G. I. El Grafitti como escritura alterna <<yo>>. In: CASTILLO GÓMEZ, A.; SIERRA BLAS, V. (orgs). Mis primeiros passos. Alfabetización, escuela y usos cotidianos de la escritura (siglos XIX e XX). Madrid: Trea Ediciones, 2008, p. 281-299.

FOUCAULT, M. As palavras e as coisas. Trad. Salma Tannus Muchail. São Paulo: Martins Fontes, 2002.

Vigiar e Punir. Editora Vozes: Petrópolis, 2004.

HABERMAS, J. Mudança estrutural da esfera pública: investigações quanto a uma categoria da sociedade burguês. Tradução de Flávio R. Kothe. Rio de Janeiro: Tempo Brasileiro, 1984.

IAPECHINO, M. N. K. Muros da Univer(c)idade: identidade, memória e sócio-história discursiva. Disponível em: http://www.fflch.usp.br/dlcv/enil/pdf/80_Mari_Noeli_KI.pdf. Acesso em: 05 mar. 2015.

LEFEBVRE, H. A vida cotidiana no mundo moderno. São Paulo: Ática, 1991.

PEIXER, Z. I. A cidade e seus tempos: o processo de constituição do espaço urbano em Lages. Lages: Editora da Uniplac, 2002. 